\title{
A uma passante
}

\author{
Ilustragão: Paula Watzko \\ Traducäo \& Roteiro: Francisca Y Silveira \\ Diagramacão: Thiago B H Silveira
}




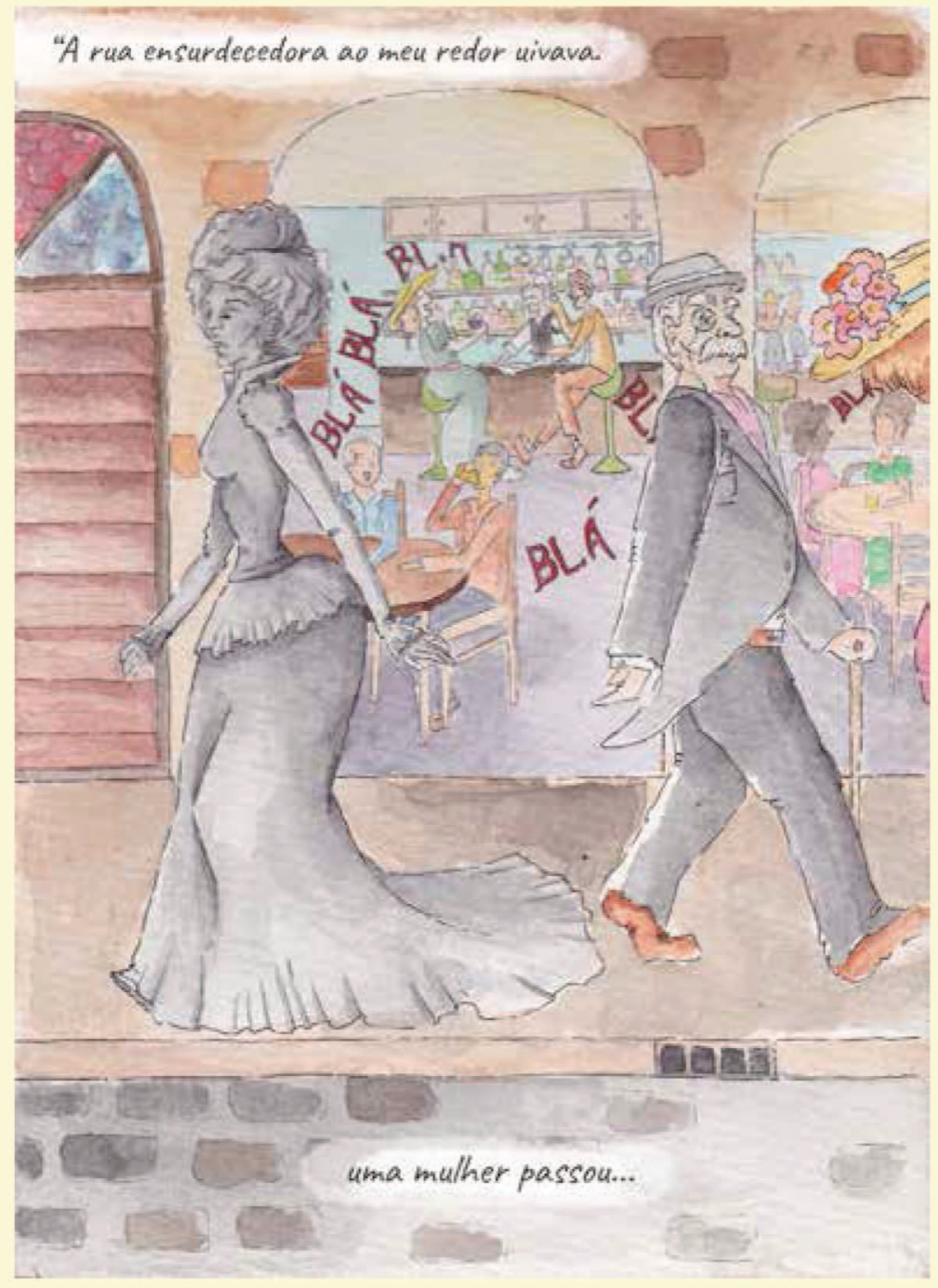

Cad. Trad., Florianópolis, v. 38, n $^{0}$ esp. Baudelaire 150 anos, p. 162-166, ago-dez, 2018 


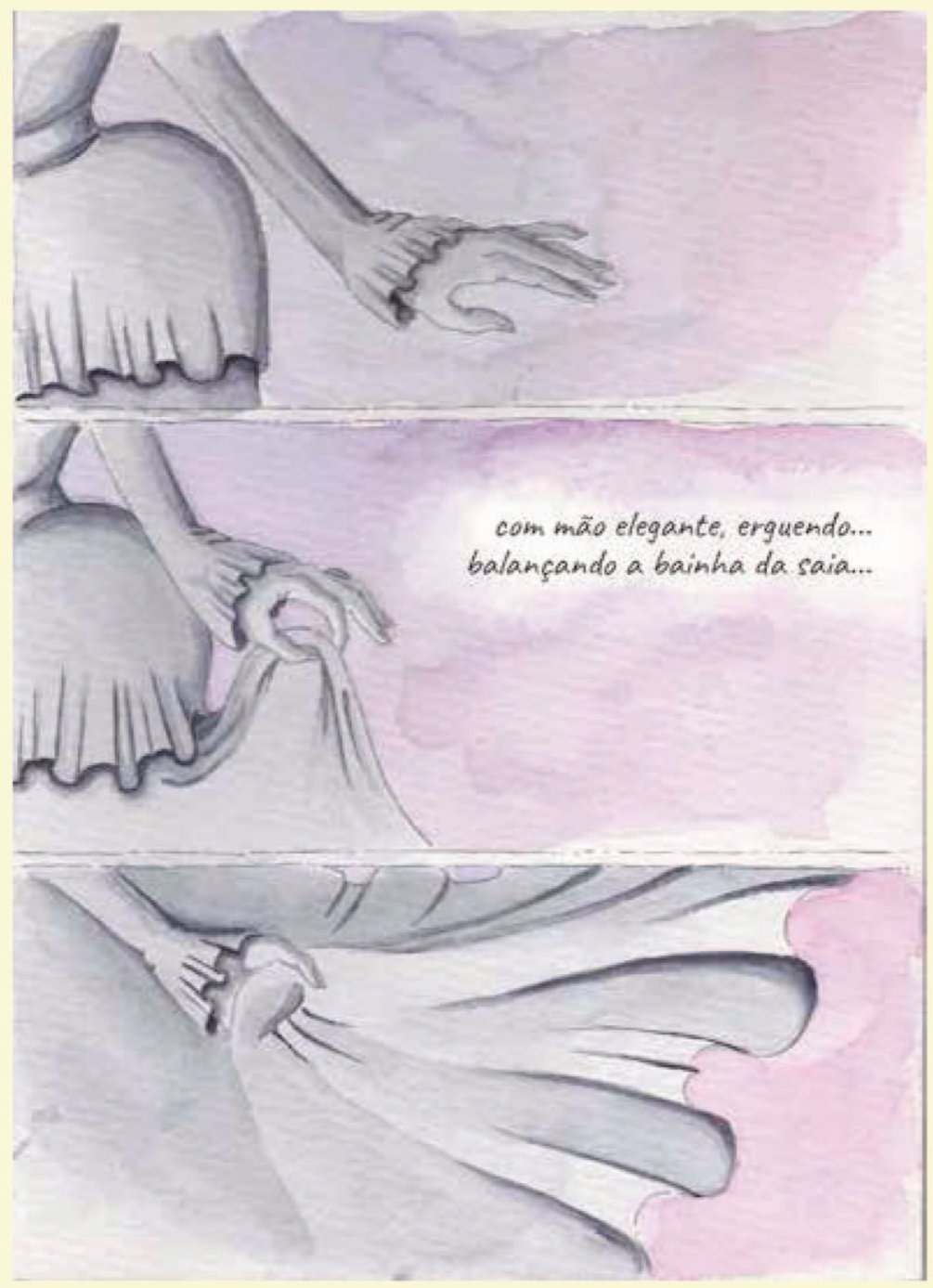

Cad. Trad., Florianópolis, v. 38, $n^{0}$ esp. Baudelaire 150 anos, p. 162-166, ago-dez, 2018 


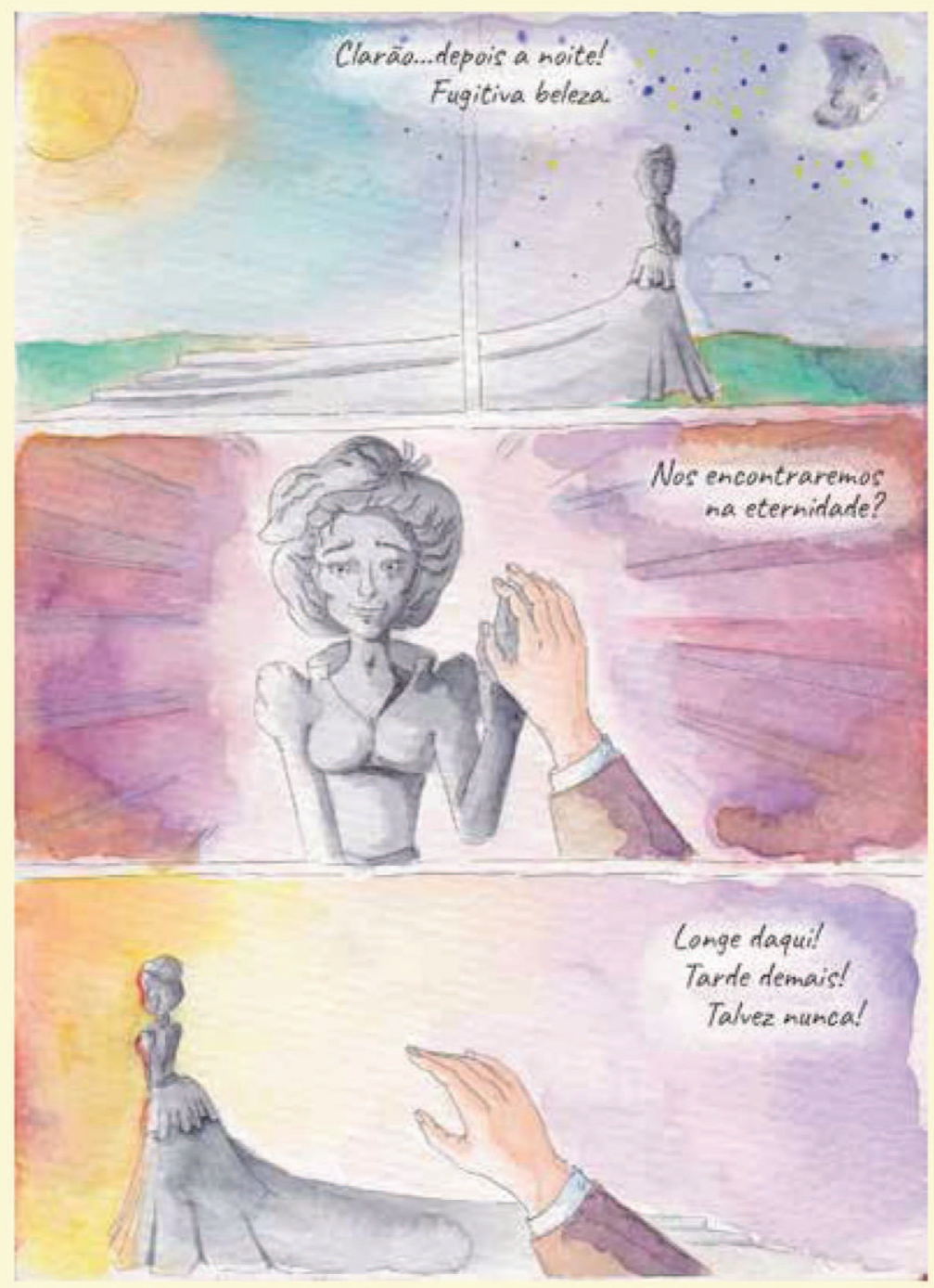

Cad. Trad., Florianópolis, v. 38, n $^{0}$ esp. Baudelaire 150 anos, p. 162-166, ago-dez, 2018 


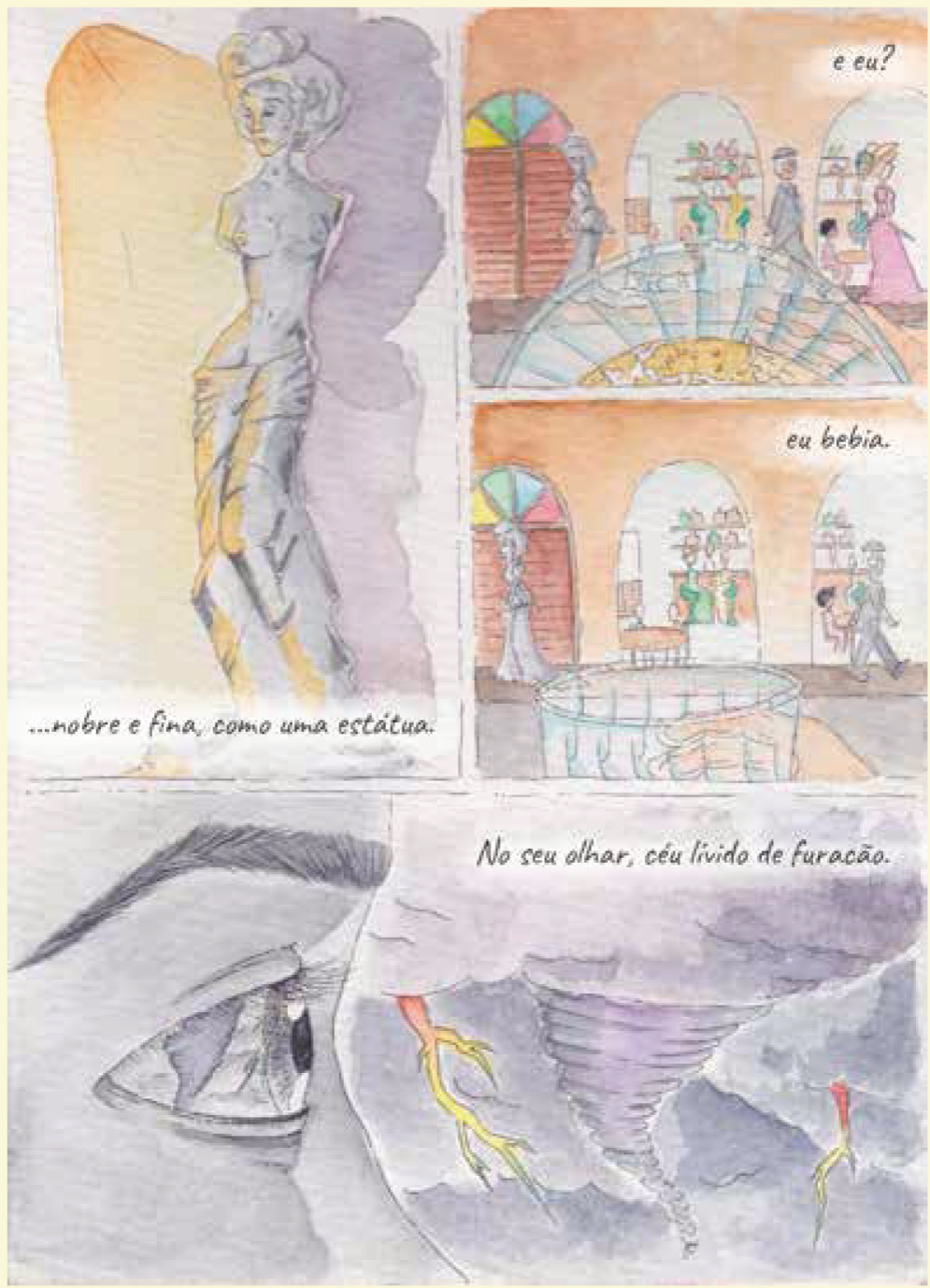

Recebido em: 28/08/2018 Aceito em: 11/10/2018 Publicado em dezembro de 2018

Francisca Ysabelle Manríquez Reyes Silveira. ORCID: https://orcid.org/00000002-1125-2380

Paula Watzko. ORCID: https://orcid.org/0000-0002-3789-0700

Cad. Trad., Florianópolis, v. 38, $\mathbf{n}^{0}$ esp. Baudelaire 150 anos, p. 162-166, ago-dez, 2018 